André Luiz Anjos de Figueiredo

Seleção e contratação de prestadores de serviços logísticos para uma empresa de mídia de jornal: Um estudo de caso

Dissertação de Mestrado (Opção profissional)

Dissertação apresentada como requisito parcial para obtenção do título de Mestre (opção profissional) pelo Programa de Pós-Graduação em Engenharia de Produção do Departamento de Engenharia Industrial da PUC-Rio.

Orientador: Prof. Nélio Domingues Pizzolato

Rio de Janeiro

Setembro de 2007 
André Luiz Anjos de Figueiredo

\section{Seleção e contratação de prestadores de serviços logísticos para uma empresa de mídia de jornal: Um estudo de caso}

Dissertação apresentada como requisito parcial para obtenção do título de Mestre (opção profissional) pelo Programa de Pós-Graduação em Engenharia de Produção do Departamento de Engenharia Industrial da PUC-Rio. Aprovada pela Comissão Examinadora abaixo assinada.

Prof. Nélio Domingues Pizzolato

Orientador

PUC - RIO

Prof. Luiz Felipe Roris Rodriguez Scavarda do Carmo

PUC - RIO

Prof. Edson Jose Dalto

IBMEC - RIO

Prof. José Eugênio Leal

Coordenador Setorial do Centro Técnico Científico - PUC-Rio

Rio de Janeiro, 05 de setembro de 2007 
Todos os direitos reservados. É proibida a reprodução total ou parcial do trabalho sem autorização da universidade, do autor e do orientador.

\section{André Luiz Anjos de Figueiredo}

Graduado em Administração de Empresas pela Universidade Santa Úrsula. Atua na área de logística desde 1999.

Ficha Catalográfica
Figueiredo, André Luiz Anjos de
Seleção e contratação de prestadores de serviços logísticos para uma empresa de mídia de jornal : um estudo de caso / André Luiz Anjos de Figueiredo orientador: Nélio Domingues Pizzolato. - 2007.
89 f. : il. ; $30 \mathrm{~cm}$
Dissertação (Mestrado em Engenharia Industrial)-Pontifícia Universidade Católica do Rio de Janeiro, Rio de Janeiro, 2007.
Inclui bibliografia
1. Engenharia industrial - Teses. 2. Prestadores de serviços logísticos. 3. Operador logístico. 4. Seleção. 5. Contratação. 6. Terceirização. I. Pizzolato, Nélio Domingues. II. Pontifícia Universidade Católica do Rio de Janeiro. Departamento de Engenharia Industrial. III. Título.

CDD: 658.5 
Ao meu filho Gabriel que eu amo muito.

A minha esposa Elisabete.

Aos meus pais Neyde e Carlos.

A minha irmã Ana e sua família.

A todas as pessoas que precisam de ajuda nesse planeta. 


\section{Agradecimentos}

Aos meus pais Carlos e Neyde pela amizade, pelo carinho e amor.

A minha esposa Elisabete por cuidar da administração do lar nesse período e pelo carinho e amor.

Ao meu filho Gabriel pelos beijos dados no papai quando estava estudando, e por sempre dizer que me ama e que me acha bonito.

Ao professor Nélio Domingues Pizzolato pelos bons papos que trocamos nesse período e por demonstrar apreço aos alunos e ao ensino em geral.

Ao professor Luiz Felipe Scavarda por ser um grande incentivador dos alunos e pelo incentivo que o mesmo me deu durante os dois anos de estudo no mestrado.

A Deus e Jesus Cristo por terem me permitido ter completado esse mestrado. 


\section{Resumo}

Figueiredo, André Luiz Anjos; Pizzolato, Nélio Domingues. Seleção e contratação de prestadores de serviços logísticos para uma empresa de mídia de jornal: Um estudo de caso. Rio de Janeiro, 2007. 89p. Dissertação de Mestrado (Opção profissional) - Departamento de Engenharia Industrial, Pontifícia Universidade Católica do Rio de Janeiro.

Práticas de terceirizações logísticas vêm sendo largamente utilizadas por empresas do Brasil e do mundo. A terceirização logística no Brasil já é um fato, e as empresas já perceberam as vantagens de terceirizar as atividades que não fazem parte de suas atividades fim para outras empresas especialistas em qualquer serviço logístico, os operadores logísticos. Metas como redução de custos, melhorias no nível de serviço e redução de ativos na operação contribuem para a prática da terceirização, tornando mais competitivas as empresas contratadoras de serviços. Dentro desse contexto, este trabalho descreve e analisa um estudo de caso de seleção e contratação de um prestador de serviços logísticos (PSL) para a Infoglobo, que é uma das principais empresas de mídia impressa do Brasil. O objetivo principal desta dissertação é analisar o processo de seleção e contratação de um prestador de serviços logísticos, de acordo com a literatura pesquisada. As conclusões indicam que a Infoglobo teve um processo de seleção e contratação estruturado, e segue a tendência da literatura atual de terceirização logística em relação aos motivadores da terceirização, atributos desejados dos PSLs, classificação e segmentação dos terceiros, fontes de informação para o processo seletivo, acordos de nível de serviço, compartilhamento de ganhos e relacionamento entre contratante e contratado.

\section{Palavras-chave:}

Prestadores de serviços logísticos; operador logístico; seleção; contratação; terceirização. 


\section{ABSTRACT}

Figueiredo, André Luiz Anjos; Pizzolato, Nélio Domingues. Selection and hiring of third-party logistics firms for a newspaper media company: A Case Study. Rio de Janeiro, 2007. 89p. Dissertação de Mestrado (Opção profissional) - Departamento de Engenharia Industrial, Pontifícia Universidade Católica do Rio de Janeiro.

Outsourcing logistics practices have being widely used for Brazilian and world companies. The outsourcing logistics in Brazil is already a fact, and the enterprises have realized the advantages of outsourcing for 3PL specialists of activities that do not belong to the scope of its own core business. Goals such as cost reduction, service level improvements, operation assets reduction contribute for outsourcing practices, making the enterprises more competitive. Given this context, the case study examined in this dissertation describes and analyzes a selection and hiring practices of third-party logistics for Infoglobo, one of the main newspapers media companies in Brazil. The main objective of this dissertation is to analyze the 3PL outsourcing process in accordance with the surveyed literature. The study has enabled us to identify that Infoglobo had a structured outsourcing process, and followed the trend of the current outsourcing literature, specially in topics such as outsourcing motivations, 3PL's desired attributes, 3PL's classification and segmentation, sources of information, service level agreement, gainsharing and relationship between the 3PL and Infoglobo.

\section{Keywords:}

Third-party logistics; logistics providers; outsourcing; selection; hiring. 


\section{Sumário}

1 Definição do problema $\quad 15$

1.1. Relevância do tema $\quad 15$

1.2. Objetivo 15

1.3. Delimitações do estudo 16

1.4. Estrutura do trabalho 16

2 Logística e gerenciamento da cadeia de suprimentos 18

2.1. Conceito de Logística 18

$\begin{array}{ll}\text { 2.2. Cadeia de suprimento } & 19\end{array}$

2.3. A terceirização - Histórico e motivadores de outsourcing de serviços logísticos 23

2.4. Algumas características da indústria de prestadores de serviços logísticos $\quad 25$

2.4.1. Surgimento 25

2.4.2. Conceituação e evolução dos prestadores de serviços logísticos 28

2.4.3. Dimensões de segmentação dos PSLs 33

2.4.4. Gestão do relacionamento entre contratante e contratado 38

2.4.5. Acordos de níveis de serviço (ANS) ou service level agreement (SLA) e compartilhamento de ganhos (gainsharing) 41 2.5. O Processo de seleção e contratação de um prestador de serviços logístico $\quad 44$

2.5.1. Introdução 44

2.5.2. O Processo de seleção de lañez et al. (2006) 45

3 Estudo de caso $\quad 48$

3.1. Introdução 48 
3.2. Breve História da imprensa e dos jornais impressos 48

3.3. Histórico da empresa 49

3.4. Metodologia 51

3.4.1. Pesquisa 51

3.4.2. Tipos de pesquisa 51

3.4.3. Coleta e análise de dados 52

3.4.4. Limitações do estudo 53

3.5. Descrição do caso 53

3.5.1. Introdução 53

3.5.2. Motivação para contratação do operador logístico 55

3.5.3. O processo de seleção e contratação 56

3.5.4. Uma proposta de seleção e contratação de PSLs:

passo a passo 57

4 Análise do caso $\quad 71$

4.1. Introdução 71

4.1.1. Motivadores da terceirização 71

4.1.2. Atributos desejados dos PSLs 72

4.1.3. Classificação e segmentação dos PSLs 75

4.1.4. Fontes de informação 77

4.1.5. Acordos de nível de serviço (ANS) e

compartilhamento de ganhos (gainsharing) 78

4.1.6. Relacionamento 80

5 Conclusões e sugestões para pesquisas futuras 82

6 Referências Bibliográficas $\quad 85$ 


\section{Lista de figuras}

Figura 1- Elementos básicos da logística 19

Figura 2 - Cadeia de logística tradicional com fatores

de pressão externa 20

Figura 3-Integração e gerenciamento dos processos de negócio através da cadeia de suprimentos.

22

Figura 4 - Evolução da terceirização da cadeia de suprimentos e dos PSLs 32

Figura 5 - Matriz de propriedade dos ativos 36

Figura 6 - Processo estruturado para seleção de um provedor de serviços logísticos. 


\section{Lista de ilustrações}

Ilustração 1 - Gráfico de comparação entre PSL's frente RFP

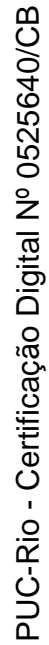




\section{Lista de quadros}

Quadro 1- Descrição detalhada de uma rota da Infoglobo

Quadro 2 - Matriz de seleção do projeto gestão de transportes 


\section{Lista de tabelas}

Tabela 1 - Origem das empresas de prestação de serviços

logísticos no Brasil 26

Tabela 2 - Diferenças entre prestadores de serviços logísticos

tradicionais e operadores logísticos integrados 30

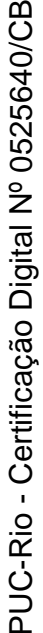

Tabela 3 - Perfil das empresas participantes do projeto

gestão de transportes 61

Tabela 4-Tabela de comparação entre PSL's após a nálise da RFP 66

Tabela 5 - Atributos e subatributos para seleção de PSL's 73

Tabela 6 - Comparação entre literatura pesquisada

e a pesquisa do projeto gestão de transportes frente à segmentação $\quad 75$ 
Salmo 23

O Senhor é meu pastor, nada me faltará. Deitar-me faz em verdes pastos, guia-me mansamente a águas tranqüilas. Refrigera a minha alma; guia-me pelas veredas da justiça por amor de seu nome.

Ainda que eu andasse pelo vale das sombras da morte, não temerei mal algum, porque Tu estás comigo; a tua vara e o teu cajado me consolam.

Preparas uma mesa perante mim na presença dos meus inimigos, unges a minha cabeça com óleo, o meu cálice transborda.

Certamente que a bondade e a misericórdia me seguirão todos os dias da minha vida e habitarei na casa do Senhor por longos dias 